\title{
Paravertebral Block
}

National Cancer Institute

\section{Source}

National Cancer Institute. Paravertebral Block. NCI Thesaurus. Code C118543.

A technique where a bolus of local anesthetic is injected in the paravertebral space, in the vicinity of the thoracic spinal nerves, resulting in ipsilateral somatic and sympathetic nerve blockade within the chest or abdomen. 